\title{
Tracking of urban aerosols using combined LIDAR-based remote sensing and ground-based measurements
}

\author{
T.-Y. He ${ }^{1}$, S. Stanič ${ }^{1}$, F. Gao ${ }^{1}$, K. Bergant ${ }^{1,2}$, D. Veberič ${ }^{1}$, X.-Q. Song ${ }^{3}$, and A. Dolžan ${ }^{4}$ \\ ${ }^{1}$ University of Nova Gorica, Nova Gorica, Slovenia \\ ${ }^{2}$ Slovenian Environment Agency, Ljubljana, Slovenia \\ ${ }^{3}$ Ocean University of China, Qingdao, China \\ ${ }^{4}$ Optotek d.o.o., Ljubljana, Slovenia
}

Correspondence to: T.-Y. He (tingyao.he@ung.si)

Received: 30 September 2011 - Published in Atmos. Meas. Tech. Discuss.: 20 October 2011

Revised: 4 April 2012 - Accepted: 15 April 2012 - Published: 2 May 2012

\begin{abstract}
A measuring campaign was performed over the neighboring towns of Nova Gorica in Slovenia and Gorizia in Italy on 24 and 25 May 2010, to investigate the concentration and distribution of urban aerosols. Tracking of two-dimensional spatial and temporal aerosol distributions was performed using scanning elastic LIDAR, operating at $1064 \mathrm{~nm}$. In addition, $\mathrm{PM}_{10}$ concentrations of particles, $\mathrm{NO}_{\mathrm{x}}$ concentrations and meteorological data were continuously monitored within the LIDAR scanning region. Based on the data we collected, we investigated the flow dynamics and the aerosol concentrations within the lower troposphere and found an evidence for daily aerosol cycles. We observed a number of cases with spatially localized increased LIDAR returns, which are associated with the presence of point sources of particulate matter. Daily aerosol concentration cycles were also clearly visible with a peak in aerosol concentration during the morning rush hours and daily plateau at around 17:00 Central European Time. We also found that horizontal atmospheric extinction at the height of $200 \mathrm{~m}$, averaged in limited region with a radius of $300 \mathrm{~m}$ directly above the ground-based measuring site, was linearly correlated to the $\mathrm{PM}_{10}$ concentration with a correlation coefficient of 0.84 . When considering the average of the horizontal atmospheric extinction over the entire scanning region, a strong dependence on traffic conditions (concentration of $\mathrm{NO}_{\mathrm{x}}$ ) in the vicinity of the ground-based measuring site was observed.
\end{abstract}

\section{Introduction}

It is well known that the presence of particulate matter in the air strongly influences atmospheric chemistry and physics (Braslau and Dave, 1973; Harshvardhan, 1993; Andreae and Crutzen, 1997; Kaufman et al., 2002; IPCC, 2007). Because of their absorbing and scattering properties, the presence of aerosol particles can directly and indirectly affect Earth's radiation budget, as well as influence cloud properties through a variety of different physical mechanisms $(\mathrm{Li}$, 1998; Andreae et al., 2004; Che et al., 2005). With the increasing urbanization and industrialization, high concentrations of particulate matter, which are often found in urban areas (Twomey et al., 1978; Hofmann, 1993; Rosenfeld, 2000), are as a rule due to a combination of many aerosol emissions, atmospheric conditions and specific topography of the area. The main increase of aerosol concentrations arises from human activities (IPCC, 2007), which may have significant environmental and climatological impacts as well as considerable effects on human health, as they may, e.g., increase the rates of the atmospheric photochemical reactions, reduce visibility and cause epidemiological diseases in general. The guidelines for the ambient air quality in Europe are set by the 2008/50/EC (Directives, 2008) of the European Commission, where the allowed upper limit of $\mathrm{PM}_{10}$ particles is set to $50 \mu \mathrm{g} \mathrm{m}^{-3}$ from 1 January 2010 and the allowed upper limit of $\mathrm{PM}_{2.5}$ particles to $25 \mu \mathrm{g} \mathrm{\textrm {m } ^ { - 3 }}$ from 1 January 2015. The need for meeting and enforcing these standards calls for extensive air quality monitoring in inhabited areas. 
Basic tools for the assessment of air quality are groundbased monitoring stations that provide continuous pointsource measurements of particulate matter concentrations, presence of various gaseous pollutants and general meteorological data. A modern remote sensing tool for the study of atmospheric aerosols is LIDAR (Measures, 1984; Grant, 1987; Killinger and Menyuk, 1987; Ansmann et al., 1992; Muller et al., 2007; Hair et al., 2008). Many LIDAR systems have been developed and implemented for measurements of aerosol optical properties (e.g. Bosenberg et al., 2003) and for air pollution studies in the atmospheric boundary layer in urban areas (e.g. Cooper and Eichinger, 1994; Devara et al., 1994; Menut et al., 1997). In addition to ground-based LIDARS, the Cloud-Aerosol LIDAR with Orthogonal Polarization (CALIOP) onboard the Cloud-Aerosol LIDAR and Infrared Pathfinder Satellite Observations (CALIPSO) has been since June 2006 providing data on the global scale for the characterization of aerosols and clouds (Winker et al., 2007, 2009, 2010). Traditional micropulse LIDARs (Spinhirne, 1993) are inexpensive and reliable; however, they do not provide scanning capability, which is needed for the acquisition of two-dimensional aerosol information. Using scanning LIDAR (Spuler and Mayor, 2005; Gao et al., 2011) for aerosol tracking and source identification studies becomes more important associated with the emissions.

On 24 and 25 May 2010, we performed a LIDAR monitoring campaign over the neighboring towns of Nova Gorica in Slovenia and Gorizia in Italy $\left(45.96^{\circ} \mathrm{N}, 13.64^{\circ} \mathrm{E}\right.$, 107 ma.s..$^{1}$ ) with the aim of tracking distributions of increased urban aerosol loading and investigating aerosol emissions. The dispersal and the trajectories of potentially hazardous pollutants were obtained from two-dimensional scanning LIDAR data on atmospheric properties with temporal resolution of about $8 \mathrm{~min}$. LIDAR results were complemented by ground-based measurements of $\mathrm{PM}_{10}$ and $\mathrm{NO}_{\mathrm{x}}$ concentration levels and measurements of local meteorological conditions.

\section{Experimental setup}

The cities of Nova Gorica and Gorizia, where the campaign was performed, are located in basin at the confluence of the Soča (Isonzo) and Vipava Rivers. From the north, they are sheltered from the direct influence of the alpine climate by an intermediate mountain range, from the west by the Goriška Brda (Collio) hills and from the southeast by the high Karst plateau, and are thus protected against the cold Bora wind, which affects most of the neighboring areas in the Slovenian littoral (Alpers et al., 2007), retaining mild Mediterranean climate throughout the year. In a typical anticyclonic situation, which was present during the campaign, there are generally mild breezes from E-NE in the nighttime and comparatively stronger winds in the daytime from the Adriatic

\footnotetext{
1 a.s.l. stands for "above sea level".
}

Sea in the SW, which is about $20 \mathrm{~km}$ away. In an environment with very scarce precipitation from spring to late autumn (Gasith and Resh, 1999) and a presence of day-night wind reversal and basin-like terrain configuration, the risk of increased aerosol loading in urban settings is expected to be high, which calls for a systematic monitoring effort for quantitative estimation of concentration levels as well as spatial and temporal variability of aerosols. The present monitoring campaign was the first attempt in Slovenia to address this problem using a combination of remote sensing and groundbased monitoring.

\subsection{Remote sensing}

Remote sensing was performed using a bi-axial scanning mobile LIDAR. The device was designed for day and nighttime studies of tropospheric conditions (He et al., 2010) and provides automatic scanning in both azimuth and elevation angle with an angular resolution of $0.1^{\circ}$. The LIDAR was set up at an elevated site northeast from Nova Gorica (305 m a.s.l., $200 \mathrm{~m}$ above the basin ground), with clear horizontal visibility over the entire region of interest (Fig. 1). A pulsed $\mathrm{Nd}$ :YAG Laser ${ }^{2}$ was used as the transmitter, providing $8 \mathrm{~ns}$ width pulses with a maximum repetition rate of $10 \mathrm{~Hz}$ at 266 and $1064 \mathrm{~nm}$. In this study, only the infrared channel was used to minimize the amount of molecular scattering relative to particulate scattering. The pulse energy was set to $40 \mathrm{~mJ}$ in order to prevent saturation of the receiver in the near field. Backscattered light was collected by a Newtonian telescope with a diameter of $300 \mathrm{~mm}$. As a result of the non-coaxial configuration of the transmitter and the receiver, the complete overlap region of the system starts from around $700 \mathrm{~m}$. For the purpose of this study, LIDAR return signal was simply discarded in the first few hundred meters, where the overlap was not complete. To suppress the background in daytime operation, an adjustable iris was placed at the focus of the telescope and a $1 \mathrm{~nm}$ interference filter ${ }^{3}$ centered at $1064 \mathrm{~nm}$ was used. The signal was detected by an IR-enhanced avalanche photodiode (APD $)^{4}$. Data acquisition was performed using a Licel transient recorder ${ }^{5}$ with 12-bit resolution at $40 \mathrm{MHz}$ sampling rate in combination with our own $\mathrm{C}++$ (Linux) based data acquisition software. These digitization parameters yield a range resolution of $3.75 \mathrm{~m}$ and a maximum theoretical detection range of $61.4 \mathrm{~km}$.

To observe two-dimensional temporal and spatial distributions of aerosols, two scan patterns were executed: range height indicator (RHI) scan and plane position indicator (PPI) scan. In RHI scan, the elevation angle was increased in $1^{\circ}$ steps from $4^{\circ}$ to $45^{\circ}$ (covering a range of $41^{\circ}$ ) at a constant azimuth angle of $230^{\circ}$. In PPI scan the elevation angle

\footnotetext{
${ }^{2}$ Big Sky CFR400 by Quantel, France.

${ }^{3}$ Barr Associates Inc., USA.

${ }^{4}$ EG \& G C30954/5E, URS Corporation, USA.

${ }^{5}$ TR40-160 transient recorder, Licel, Germany.
} 


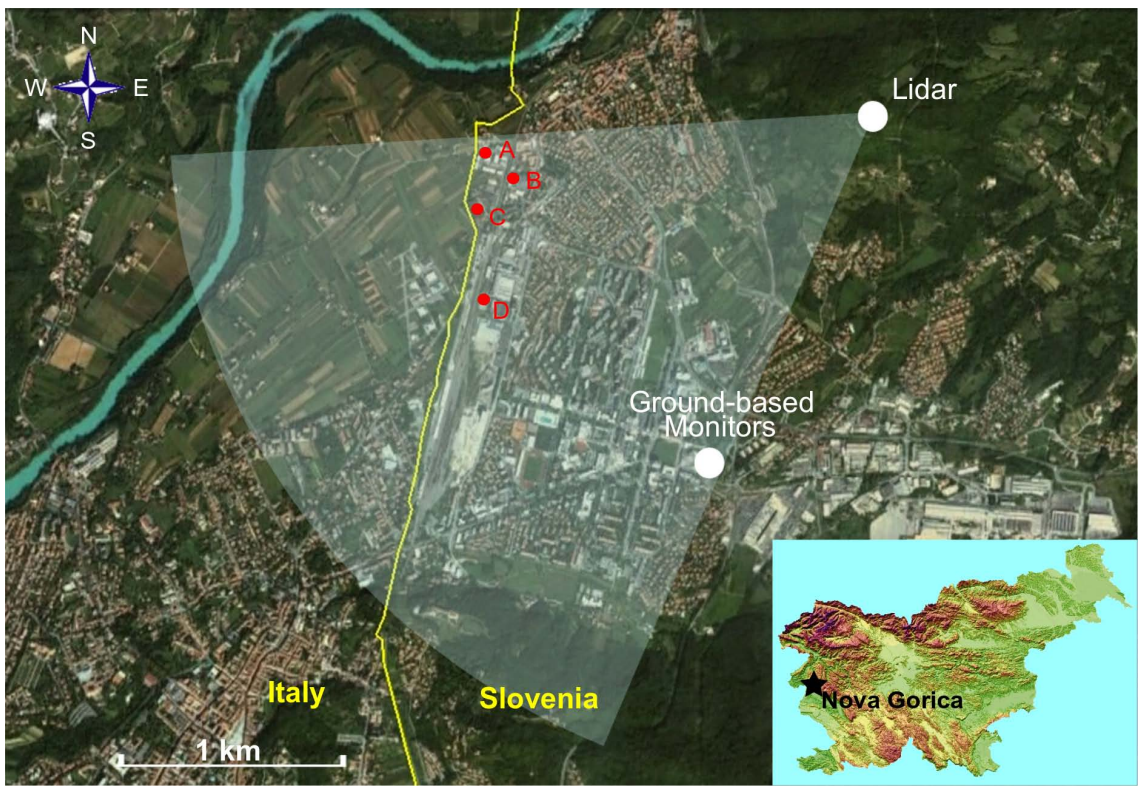

Fig. 1. Top view of the scanning region (light-colored shadow) and the LIDAR site $\left(45.96^{\circ} \mathrm{N}, 13.64^{\circ} \mathrm{E}, 305 \mathrm{~m}\right.$ a.s.1., $200 \mathrm{~m}$ above the town). $\mathrm{PM}_{10}, \mathrm{NO}_{\mathrm{x}}$ and meteorological data were monitored at the ground level. Red points denote the locations of the identified aerosol sources and the yellow line the border between Slovenia and Italy.

was set to zero and the azimuth angle was changed in $2^{\circ}$ steps in counterclockwise direction from $267^{\circ}$ to $205^{\circ}$, covering a range of $62^{\circ}$. At each step, 150 laser shots were averaged and each scan took approximately $8 \mathrm{~min}$ to complete.

\subsection{Ground-based measurements}

Due to the elevated risk of increased aerosol loading in Nova Gorica region, the concentration of $\mathrm{PM}_{10}$ particles is being continuously monitored by the Slovenian Environmental Agency. The monitoring site is located within the scanning area in a vicinity of a busy road in Nova Gorica (Fig. 1). True mass concentrations were provided by an ambient particulate monitor ${ }^{6}$, positioned $2 \mathrm{~m}$ above the ground. In addition, $\mathrm{NO}_{\mathrm{x}}$ concentrations and meteorological data (wind speed and direction $10 \mathrm{~m}$ above the ground, temperature and relative humidity $2 \mathrm{~m}$ above the ground) were also collected at the same site. All ground-based data were averaged every hour except for the wind speed and direction, which were averaged every half an hour.

\section{Analysis of LIDAR data}

The LIDAR return signal along a single line of sight can be modeled (Collis and Russel, 1976) as

$P(r)=\frac{C E_{0} \beta(r)}{r^{2}} \exp \left[-2 \int_{0}^{r} \alpha\left(r^{\prime}\right) \mathrm{d} r^{\prime}\right]$,

\footnotetext{
${ }^{6}$ TEOM series $1400 \mathrm{a}$ ambient particulate monitor, Thermo Electron Corporation, USA.
}

where $P(r)$ is the received signal, $C$ the LIDAR system constant including the losses in the transmitting and receiving optics and the effective receiver aperture, $E_{0}$ the laser pulse energy, $\beta$ the volume backscatter $\left(\mathrm{m}^{-1} \mathrm{sr}^{-1}\right)$, and $\alpha$ the extinction coefficient $\left(\mathrm{m}^{-1}\right)$. Raw data were normalized to the laser energy, and the flat baseline of each return, which is proportional to the intensity of background noise, was subtracted. Background noise was defined as an average of data points sampled at the far end of the trace. Each LIDAR return was then corrected for inverse range-squared dependence (Measures, 1988). To improve the signal-to-noise ratio, a five-point gliding type radial basis spatial filter algorithm with weights given by Pascal's triangle was employed. Maximum detectable range with signal-to-noise ratio larger than one was then found to be about $5 \mathrm{~km}$. Spatial distribution of the range-corrected LIDAR return signal obtained by both RHI and PPI scanning was presented by Cartesian 2-D scans. To fill the pixels where no LIDAR data were available, a weighted value was reconstructed using a barycentric interpolation scheme (Min, 2004) between successive step profiles with a $5 \mathrm{~m}$ resolution of the Cartesian 2-D grid.

To be able to normalize LIDAR return signals to aerosol concentrations, they need to be transformed into atmospheric extinction profiles. In urban areas, Klett solution (Klett, 1981) of the vertical extinction profile can be highly erroneous because of the relatively large uncertainty of the extinction-to-backscatter ratio (so-called LIDAR ratio). The multiangle method (Kano, 1968; Hamilton, 1969; Filipčič et al., 2003) is a possible way to obtain vertical extinction profiles from different elevation angle data obtained by scanning LIDAR under the assumption of horizontal atmospheric 
homogeneity and without the need to select specific LIDAR ratio. As the atmospheric boundary layer over urban areas is generally turbulent and heterogeneous (Spinhirne et al., 1980; Kovalev and Eichinger, 2004), this method is rarely used due to the inaccuracy of the horizontal atmospheric homogeneity assumption along any single trace. However, as aerosol fluctuations in horizontal directions are mostly random, LIDAR return data averaged over the entire horizontal scan do allow for a relatively accurate calculation of spatially-averaged aerosol extinction at a specific height.

As the LIDAR operated in the infrared part of the spectrum, the contribution from molecular scattering to extinction and backscatter coefficients was considered to be negligible. Effects of atmospheric inhomogeneities on the aerosol extinction coefficient $\alpha$ (which may be caused by localized pollution sources and meteorological conditions) were minimized by using the average of the LIDAR $S$-function,

$\bar{S}(r)=\left\langle\ln \left[r^{2}\left(P(r)-P_{\mathrm{bg}}\right)\right]\right\rangle=\ln (C \beta)-2 \alpha r$,

over each horizontal PPI scan in the deconvolution process, where $P_{\text {bg }}$ represents the intensity of the background noise. In the averaging, directions with apparent nonlinear data (e.g. with the presence of point sources) were excluded. Horizontal atmospheric extinction coefficient at a specific height was obtained using the slope method (Collis, 1966), as the slope of the least squares straight line fit to $\bar{S}(r)$ through the considered range (Fig. 2). The deviations of atmospheric extinction coefficient $\alpha$ from linearity are a suitable criterion for the detection of the extent of horizontal heterogeneity of the atmosphere and thus can be used as an estimator for the quality of the retrieved data.

The total uncertainty mainly related to the LIDAR-based measurement of aerosol extinction coefficient arose from three major sources: the uncertainty of the system constant factor $C$, the error in the background $P_{\text {bg }}$ subtraction, and the horizontal atmospheric inhomogeneity (Eq. 2). The contribution of the system constant uncertainty for the case of thermally stabilized LIDAR return detection system is typically less than 0.05 (e.g. PerkinElmer, 2011). Relative uncertainty arising from background subtraction is related to the signal-to-noise ratio of the LIDAR system. As the LIDAR signal decreases with distance as $1 / r^{2}$ (Eq. 1), this uncertainty tends to be smaller closer to the LIDAR site and greater further away from the LIDAR. In our case, the deviation of background noise was $0.12 \mathrm{mV}$ out of approximately $5 \mathrm{mV}$ at the range of $3.5 \mathrm{~km}$. The uncertainty from background noise subtraction was on average found to be 0.03 . Dominant contribution to the total uncertainty of the measurement was due to horizontal atmospheric inhomogeneities. These were estimated by considering the nonlinearity of the LIDAR $S$ function signal $S(r)$ for horizontal traces with different azimuth angles at a fixed distance from the LIDAR site (e.g. azimuthal nonlinearity), and the nonlinearity of the averaged $S$-function signal $\bar{S}(r)$ within the considered range, where

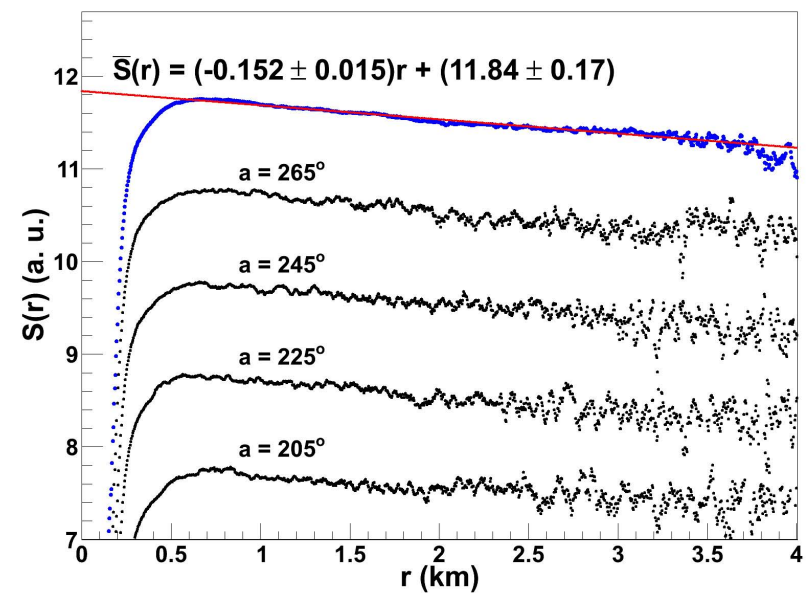

Fig. 2. Averaged $S$-function for different horizontal directions over the PPI scan performed at 11:54CET on 25 May 2010, with apparent nonlinear data excluded. The line $\bar{S}(r)=(-0.152 \pm 0.015) r+(11.84 \pm 0.17)$ is a result of least squares linear fit in the range between 0.8 and $3.5 \mathrm{~km}$, yielding a correlation coefficient of 0.94 . The resulting horizontal atmospheric extinction coefficient $\alpha$ is $0.076 \mathrm{~km}^{-1}$, with relative error of about 0.1 due to atmospheric inhomogeneity. $S$-functions with azimuthal angles of $265^{\circ}, 245^{\circ}, 225^{\circ}$, and $205^{\circ}$ are also shown with an incremental shift minus one from the averaged value.

the apparently nonlinear traces (less than $10 \%$ of the full scan) were excluded from the calculation. The upper limits on azimuthal nonlinearities were calculated at the distance of $3.5 \mathrm{~km}$ from the LIDAR site, which was chosen to maximize the effects of heterogeneity due to geometrical distance between successive azimuthal profiles. Total relative uncertainty due to horizontal inhomogeneity was estimated to be less than 0.2 . These three uncertainties are assumed to be statistically independent; a total relative uncertainty of aerosol extinction coefficient was estimated to be less than 0.21. Another possible source of uncertainty, which was not explicitly accounted for in this study, is the variability of the LIDAR ratio over the scanning area; it was however minimized by excluding LIDAR data traces with apparently non-linear behavior (distinct point sources) of the averaged $S$-function (Fig. 2).

\section{Results and discussion}

Using the LIDAR data from the campaign and the standard ground-based monitoring data, several case studies were investigated, including the observation of the vertical structure dynamics in the lower troposphere, the identification of aerosol point sources and the study of daily aerosol cycles. In addition, a correlation study between the LIDAR-based and ground-based data was also performed. 

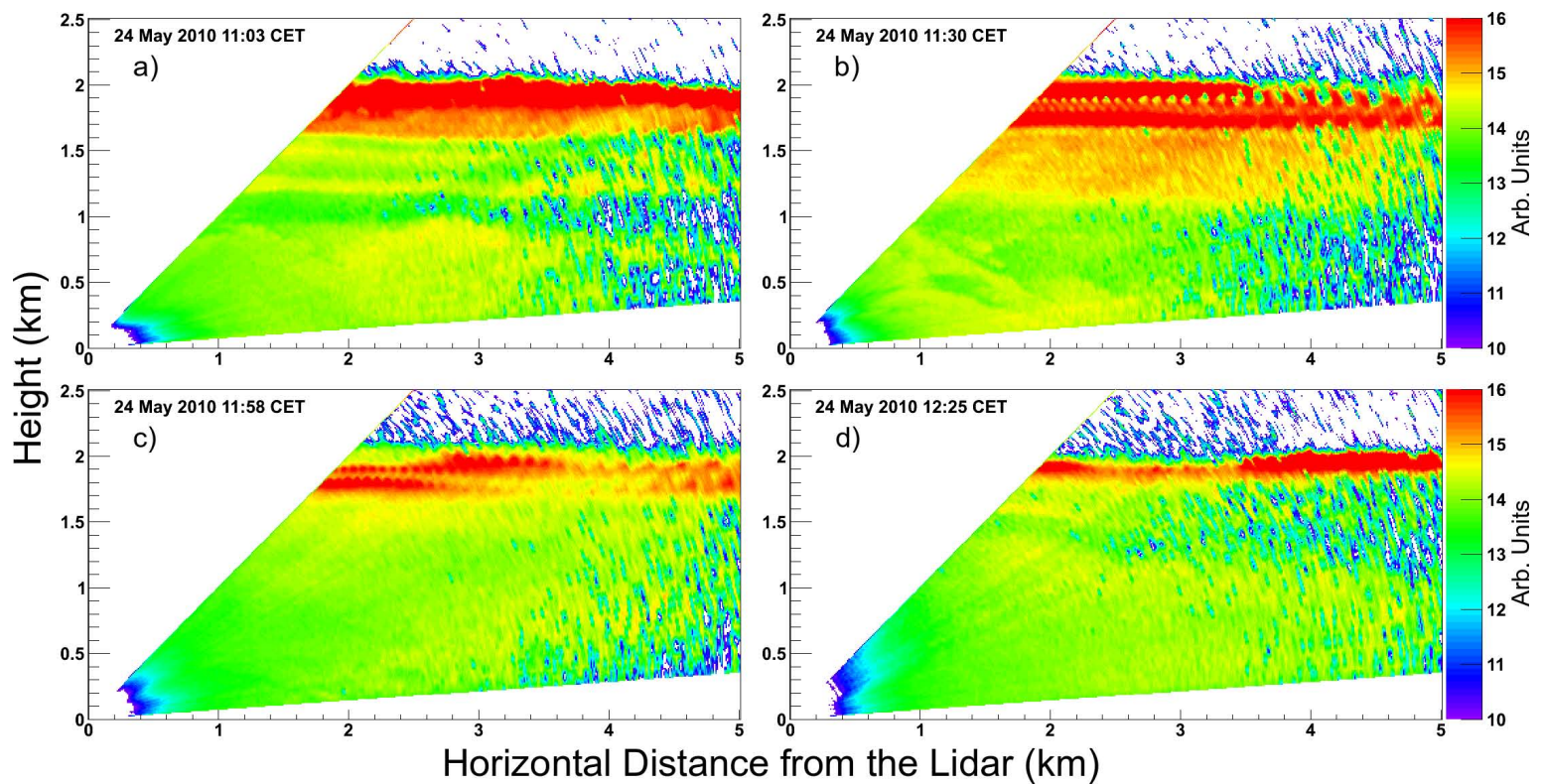

Fig. 3. Time series of vertical RHI scans showing the logarithm of the range-corrected LIDAR signal for elevation angles from $4^{\circ}$ to $45^{\circ}$ with angular step of $1^{\circ}$. The scans were performed between 11:00 and 12:30 CET on 24 May 2010. The presence of a lower layer of clouds can be seen throughout the scanning period at the altitude of $2 \mathrm{~km}$, relative to the LIDAR site. Above $2 \mathrm{~km}$, LIDAR signal is effectively blocked by the clouds.
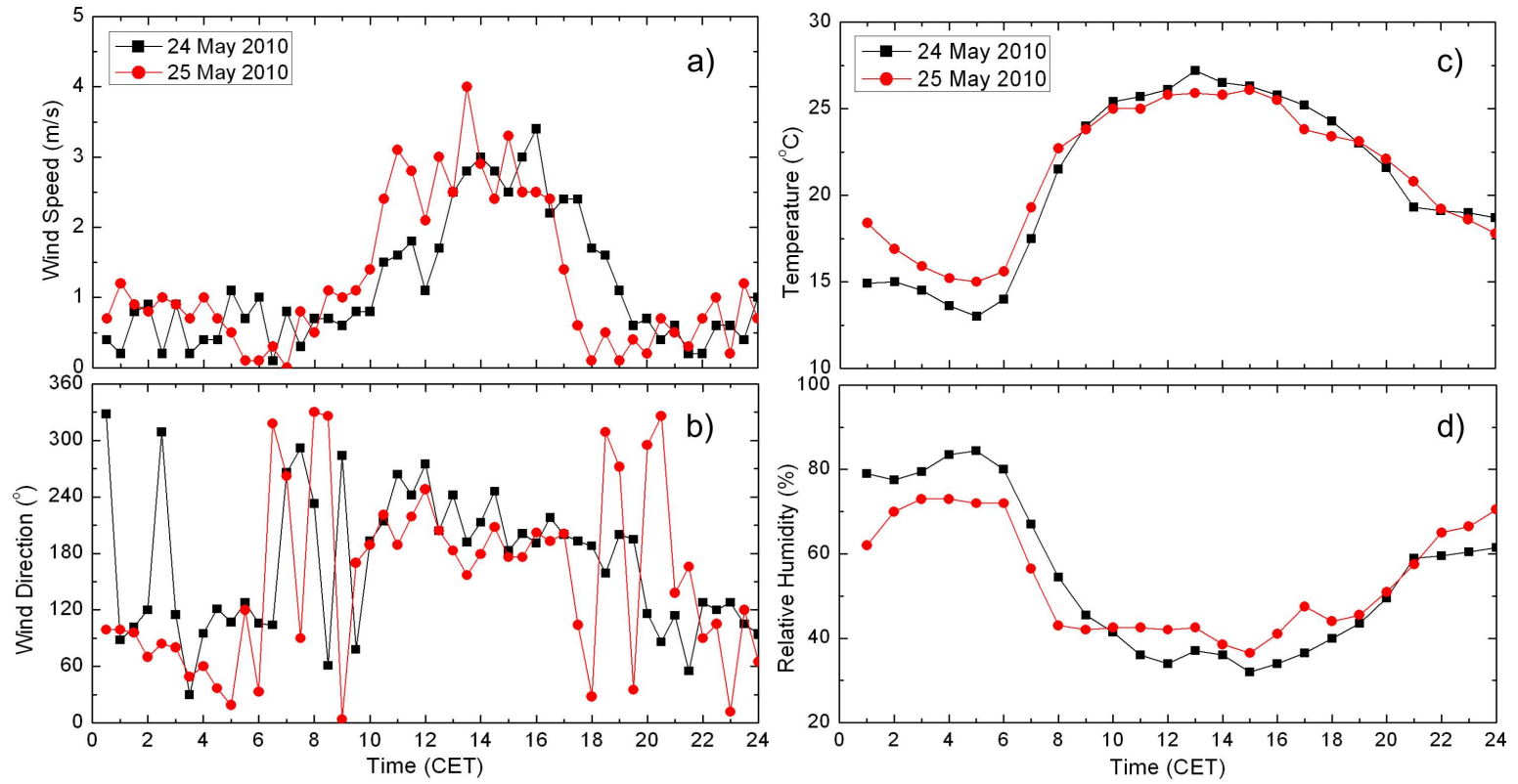

Fig. 4. Meteorological data for Nova Gorica from 24-25 May 2010. Wind information was obtained $10 \mathrm{~m}$ above the ground and the temperature and relative humidity $2 \mathrm{~m}$ above the ground.

\subsection{Structure of the lower troposphere}

In the daytime and under unstable, windy conditions, the lower troposphere is usually well mixed due to convection or vertical wind shear. On the other hand, in stable atmospheric conditions some horizontally stratified layers can be formed, especially during the night. In our case study we used vertical RHI scans to reveal vertical distribution of aerosols in the lower troposphere. The main purpose of the case study was to investigate the transition from the horizontally stratified lower troposphere formed during the night to well mixed lower troposphere due to the increased thermal convection 
during the daytime. An example of temporal development of vertical structure of the lower troposphere, illustrated by a series of RHI scans performed from 11:00 to $12: 30 \mathrm{CET}^{7}$ on 24 May 2010, is shown in Fig. 3. At 11:03, lower troposphere was still horizontally stratified (Fig. 3a), and several optically thin aerosol layers can be seen up to $1.6 \mathrm{~km}$ above the LIDAR site. At the height of about $2 \mathrm{~km}$, a layer of low level clouds was also present. In the next one and a half hour (Fig. 3bd), increased solar radiation caused the low clouds to slowly diminish and therefore more solar radiation reached the surface. Solar heating of the surface and consequential heating of the air at the surface intensified thermal convection and mixing of the air in the lower troposphere, which caused the degradation of the stratified layers. The effect of the heating was additionally confirmed by an evident increase of air temperature and the increase in wind speed (Fig. 4a) in the period between 11:00 and 12:30. The described turbulent atmospheric conditions due to changing structure of the lower troposphere are expected to be the main contribution to the uncertainty of the horizontal aerosol extinction coefficient (Fig. 7), whose relative errors during this period increased for about $50 \%$, with respect to earlier and later measurements.

\subsection{Identification of aerosol sources}

In urban areas, main aerosol sources are expected to be localized exhausts from industrial and domestic emissions and traffic along the roadways. Individual aerosol emissions can not be distinctly visible in the single point ground-based $\mathrm{PM}_{10}$ and $\mathrm{NO}_{\mathrm{x}}$ monitoring data because of spatial and temporal averaging; however, time series of the remote sensing scanning data can reveal the exact locations of the sources and complex dispersion paths of the plumes. We attempted to identify aerosol sources from the spatial distribution of the logarithm of the range-corrected LIDAR return signal in the horizontal PPI scans.

During the LIDAR campaign, a total of eight distinct cases of localized increases of LIDAR return were observed, all of them in the industrial area northwest of Nova Gorica. Using the range and azimuth information from horizontal PPI scans, these cases were found to appear at four different locations (Fig. 1) with polar coordinates of $\mathrm{A}=\left[1.7 \mathrm{~km}, 265^{\circ}\right]$, $\mathrm{B}=\left[1.55 \mathrm{~km}, 262^{\circ}\right], \mathrm{C}=\left[1.7 \mathrm{~km}, 258^{\circ}\right]$ and $\mathrm{D}=[1.8 \mathrm{~km}$, $245^{\circ}$ ], with respect to the LIDAR site. After visual inspection of these locations in the field, they were confirmed to be major industrial aerosol sources, namely processing plants (A) and (D), lime production plant (B) and a foundry (C). In most cases, the plume emitted from these sources was found to spread towards inhabited areas.

Examples of aerosol emissions from sources (B) and (D) can be seen in horizontal PPI sector scans performed at 09:19 and 11:28 on 25 May 2010 (Fig. 5), where both show localized increases of LIDAR return. In the scan taken at 09:19 in

\footnotetext{
${ }^{7}$ All times in this paper refer to Central European Time (CET).
}

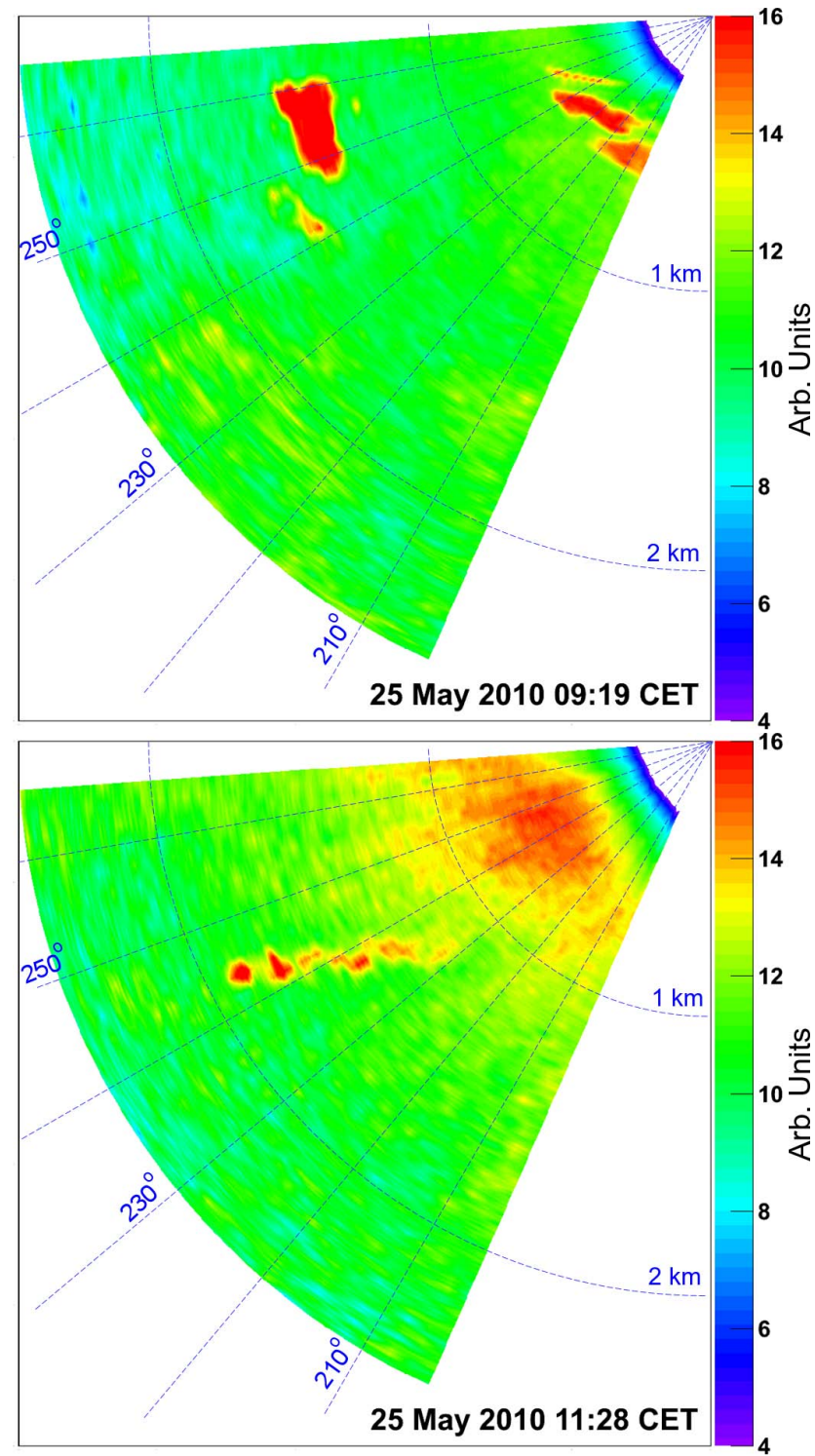

Fig. 5. Two examples of horizontal PPI sector scans showing the logarithm of the range-corrected LIDAR signal (performed at 09:19 and 11:28 CET on 25 May 2010) show localized increases of LIDAR return corresponding to aerosol emission sources (B) and (D). In the later scan, the dispersion of the plume (D) towards the NE due to the increased wind speed can be clearly seen.

calm wind conditions, the increased LIDAR return was found to be localized above the source (B) only. In the scan at 11:28, the plume from the source (D) was found to be carried in a relatively straight line towards the north-east for about $800 \mathrm{~m}$ due to the emerging southwestern wind (Fig. 4b), after which it disappeared (either blended in with background aerosols or rose above the scanning plane). Based on the logarithmic velocity law (Garratt, 1992), rapid dispersal of the plume can be explained by the presence of a stronger wind around the LIDAR scanning height. 


\subsection{Daily aerosol cycles}

In urban areas, aerosol concentration levels were found to be strongly related to human activities, which result in the appearance of prominent features in daily aerosol cycles. These cycles are clearly visible in ground-based $\mathrm{PM}_{10}$ and $\mathrm{NO}_{\mathrm{x}}$ monitoring data (e.g. Harrison et al., 1999). Daily variations of $\mathrm{PM}_{10}$ and $\mathrm{NO}_{\mathrm{x}}$ in Nova Gorica from 24-25 May 2010 are shown in Fig. 6. The increase in both $\mathrm{PM}_{10}$ and $\mathrm{NO}_{\mathrm{x}}$ concentration levels, peaking at around 08:00, was found to be present not only on these two days, but as a rule in the long-term data and can be related to the traffic emissions in the morning rush hours. In addition to the exhaust emissions, road dust picked up and injected into the boundary layer by vehicles may also be responsible for the concentration increase (e.g. Eichinger et al., 1994). The $\mathrm{NO}_{\mathrm{x}}$ concentration had an apparent low in the afternoon, while the $\mathrm{PM}_{10}$ increased and reached a plateau at around 17:00. A local $\mathrm{NO}_{\mathrm{x}}$ peak observed at around 21:00 was found to appear regularly in the Nova Gorica long-baseline environmental monitoring data and can be related to human activities. As the groundbased measurements were performed near a busy road and the largest shopping area in this region, the elevated $\mathrm{NO}_{\mathrm{x}}$ concentrations are assumed to be due to the traffic, especially as they decrease after the closure of the stores. Relatively low and constant concentrations of both $\mathrm{PM}_{10}$ and $\mathrm{NO}_{\mathrm{x}}$ during the night are expected to be the result of significantly reduced traffic and the absence of strong localized nighttime sources outside the winter season.

In the LIDAR monitoring campaign, scanning measurements were performed from 09:00 to 16:00 on 24 May 2010 and from 09:00 to 18:00 on 25 May 2010. The late morning increase of aerosol concentrations over the entire area is visible from temporal evolution of LIDAR-derived aerosol extinction, obtained from horizontal PPI scans $200 \mathrm{~m}$ above the ground (Fig. 7). Despite the fact that aerosol extinction is due to scattering on particulate matter and should therefore follow more or less the same daily pattern, several differences were found. There was a rapid decrease of aerosol concentration at the ground level after 10:00 due to the decrease of traffic intensity and the increase of the southwestern updraft wind speed (Fig. 4a), which was not observed in the scanning data. We expect this to be due to basin-like terrain configuration, so that the aerosols remained contained and were present at the LIDAR scanning height. On 25 May, a second peak in aerosol extinction was observed after 16:00, when solar radiation and wind speed (Fig. 4a) simultaneously decreased, which indicates an increase of the amount of accumulated aerosols during such conditions. The decrease of aerosol extinction between 13:00-16:00 was not observed in the $\mathrm{PM}_{10}$ measurements, which were more or less constant. In such a case, we expect the aerosol extinction decrease to be due, at least in part, to the increased water evaporation from hygroscopic aerosols (e.g. Lewandowski et al., 2010) during the daily temperature maximum (Fig. 4c). Another

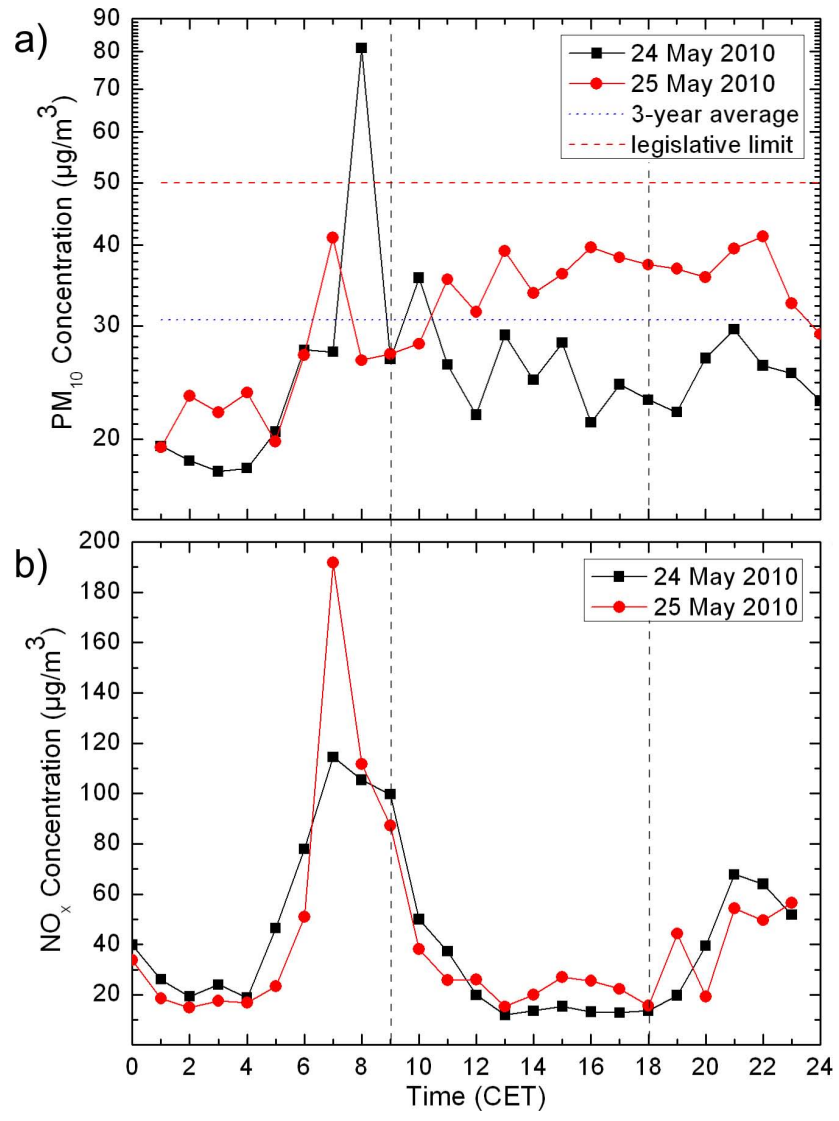

Fig. 6. Temporal evolution of $\mathrm{PM}_{10}$ and $\mathrm{NO}_{\mathrm{x}}$ concentrations for the period of 24-25 May 2010, obtained from the ground-based measurements at the monitoring station in Nova Gorica. The intervals when LIDAR measurements are available are marked with vertical dashed lines.

reason for the decrease could be that in this period the convection was the strongest. The resulting mixing of air masses and the increase of the boundary layer height would decrease aerosol concentrations in the entire Nova Gorica basin, including at the LIDAR scanning height.

\subsection{Correlation between aerosol extinction and $\mathbf{P M}_{10}$ concentration}

As the aerosol extinction is a result of Mie scattering on particulate matter in the atmosphere, it is expected to be highly correlated to particle concentrations and to depend on the size of the scatterers, which was experimentally confirmed in several studies (e.g. Del Gusta and Marini, 2000; Lagrosas et al., 2005).

In our case study, in the absence of the data regarding the distribution of aerosol size, a simple comparison of LIDARbased horizontal atmospheric extinction and ground-based $\mathrm{PM}_{10}$ concentration was made. In addition to the unknown aerosol size distribution, another major source of uncertainties was expected to originate from different locations of 


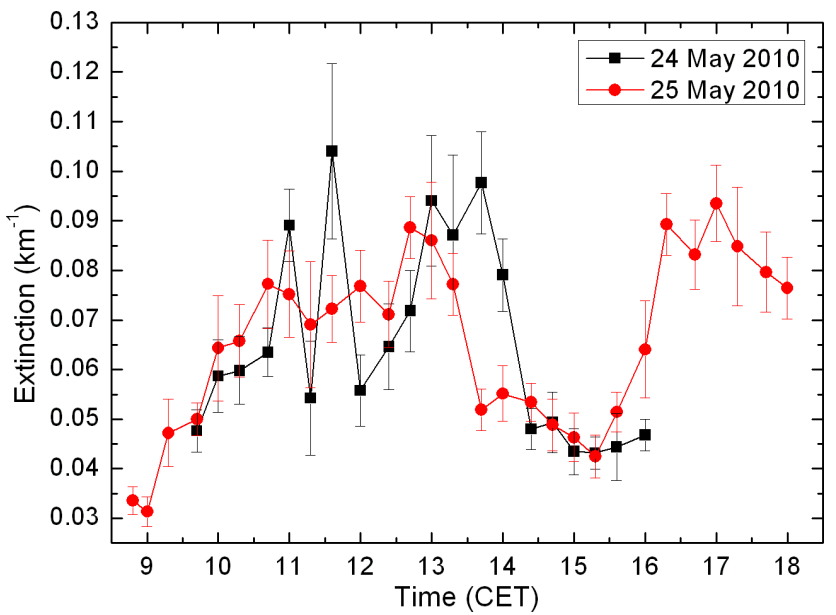

Fig. 7. Temporal evolution of LIDAR-derived aerosol extinction coefficients over the entire scanning area (with point sources excluded), $200 \mathrm{~m}$ above the town from 09:00 to 16:00 CET on 24 May 2010 and from 09:00 to 18:00 CET on 25 May 2010.

the measurements, as LIDAR measurements were performed $200 \mathrm{~m}$ above the ground, while $\mathrm{PM}_{10}$ concentration was measured at the ground level. The correlation between aerosol extinction $(\alpha)$ and $\mathrm{PM}_{10}$ concentration $(c)$ was investigated using hourly averaged data. When limiting the LIDAR scanning area to a circle with a radius $R \leq 300 \mathrm{~m}$ directly above the ground-based measurement site, the correlation was found to be linear with a slope of $\alpha=(0.002 \pm 0.00007) c$ and a correlation coefficient of 0.84 for the entire dataset (Fig. 8). Based on the assumption that aerosols with diameters up to $10 \mu \mathrm{m}$ are the main scatterers (e.g. Birmili et al., 2010; Wu et al., 2008), the extinction in the fit was constrained to zero for the limit case, when $\mathrm{PM}_{10}$ concentration was zero. In the case of an unconstrained linear fit, the constant term was also found to be consistent with zero.

Due to the basin-like terrain configuration and relatively quiet meteorological conditions, hourly averaged horizontal aerosol extinctions over the entire scanning area were expected to be correlated with the $\mathrm{PM}_{10}$ concentration as well and are included in the Fig. 8 as square-shaped red and green markers. The correlation coefficient for the entire dataset was found to be 0.4 . Detailed investigation of traffic conditions for the apparently non-correlated values with lower extinction (green markers) revealed that they represent those measurements between 13:00 and 16:00, when the traffic was low $\left(\mathrm{NO}_{\mathrm{x}}\right.$ concentrations were below $\left.27 \mu \mathrm{g} \mathrm{m}^{-3}\right)$. Both the low (green) and the high (red) traffic subsets were separately found to be linearly correlated to the $\mathrm{PM}_{10}$ concentration with slopes $\alpha_{\text {green }}=(0.0015 \pm 0.0001) c$ and $\alpha_{\text {red }}=(0.0023 \pm 0.0001) c$, correlation coefficients of 0.72 and 0.86 , respectively. In both fits, aerosol extinction was constrained to zero for the limit case, when $\mathrm{PM}_{10}$ concentration was zero. $\mathrm{PM}_{10}$ concentrations appeared to be best

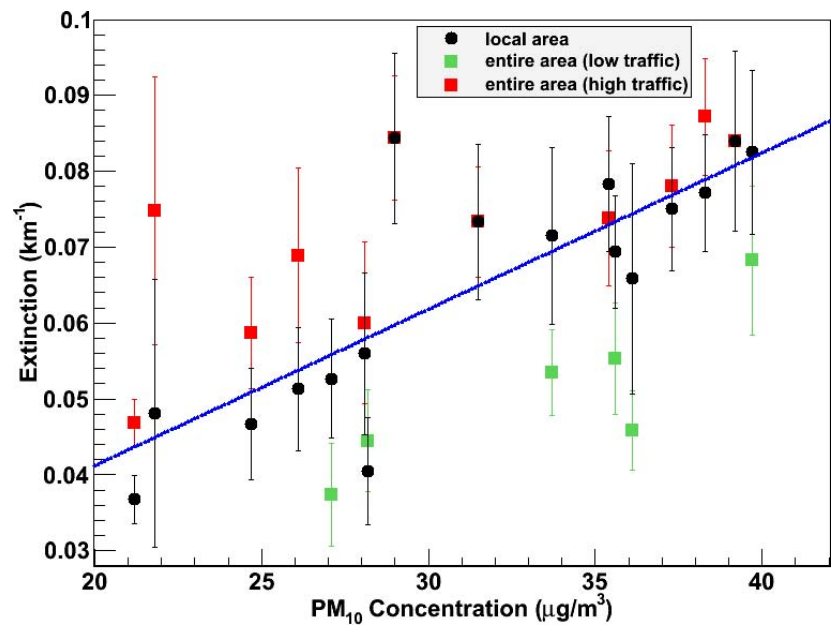

Fig. 8. The correlation between the LIDAR-derived extinction and the $\mathrm{PM}_{10}$ concentration. The extinction for the entire dataset (black points) in a localized area with a radius $R \leq 300 \mathrm{~m}$ directly above the ground-based measurement site was found to be related to the $\mathrm{PM}_{10}$ concentration with a correlation coefficient of 0.84 and a slope of $0.002 \pm 0.00007 \mathrm{~m}^{3} \mathrm{~km}^{-1} \mu \mathrm{g}^{-1}$ (blue line). Red points (correlation coefficient 0.72 ) represent the extinction values averaged over the entire scanning area for intervals of high traffic and green points (correlation coefficient 0.86 ) for periods of low traffic. In the fits, aerosol extinction was constrained to zero for the limit case, when $\mathrm{PM}_{10}$ concentration was zero.

correlated with aerosol extinctions averaged over the entire scanning area, when aerosol concentrations were not dominated by traffic contributions from the vicinity of the groundbased measuring site.

\section{Conclusions}

The case studies of aerosol monitoring performed over the neighboring towns of Nova Gorica in Slovenia and Gorizia in Italy on 24 and 25 May 2010 showed that a combination of remote sensing and in situ ground measurements provides useful additional information for the investigation of the effects of urban environment. The sources of uncertainties in the LIDAR measurements were investigated in detail, and the relative error of the aerosol extinction coefficient was found to be less than 0.21 .

Regarding the structure of the lower troposphere, complex flow dynamics between layers with increased aerosol content was observed. In the case of identification of aerosol sources, LIDAR-based remote sensing was found to be essential. Using horizontal PPI plots of the range-corrected LIDAR return signal, four distinct aerosol point sources were identified in the industrial area of Nova Gorica and later confirmed by the inspection in the field. Daily aerosol cycles, routinely observed in ground-based monitoring data, were observed in LIDAR-based data as well, with noticeable 
differences between the temporal evolution of aerosol extinction and $\mathrm{PM}_{10}$ concentration. These differences could be related to the topographical properties of the urban region, the properties of the aerosol particles or the daily meteorological conditions. Aerosol concentrations up to four times higher during the rush hours in comparison to the daily average indicate that traffic plays an important role in air pollution in the Nova Gorica/Gorizia region. Finally, an attempt was made to correlate the horizontal aerosol extinctions obtained from remote sensing to mass concentration, obtained from the measurements of $\mathrm{PM}_{10}$ concentration. The $\mathrm{PM}_{10}$ concentrations were found to be linearly correlated to the extinctions in a localized area directly above the ground-based measurement site with a correlation coefficient of 0.84 . The extinctions averaged over the entire scanning area were also found to be highly correlated to the $\mathrm{PM}_{10}$ concentrations, when they were considered separately for high and low traffic conditions. Maximum aerosol extinction of $0.1 \mathrm{~km}^{-1}$ at $1064 \mathrm{~nm}$ obtained in the campaign corresponds to about $40 \mu \mathrm{g} \mathrm{m}^{-3}$.

Acknowledgements. We wish to thank Romina Žabar and Gostilna Kekec for providing the measuring site above Nova Gorica and Tanja Bolte from Slovenian Environmental Agency for providing the ground-based monitoring data. We also acknowledge the financial support of the Slovenian Research Agency.

Edited by: G. de Leeuw

\section{References}

Alpers, W., Ivanov, A. Y., and Horstmann, J.: Bora events over the Adriatic Sea and Black Sea studied by multi-sensor satellite imagery, in: Proceedings of the International Geoscience and Remote Sensing Symposium (IGARSS), Toulouse, France, 13071313, 2007.

Andreae, M. O. and Crutzen, P. J.: Atmospheric aerosols: Biogeochemical sources and role in atmospheric chemistry, Science, 276, 1052-1058, 1997.

Andreae, M. O., Rosenfeld, D., Artaxo, P., Costa, A. A., Frank, G. P., Longo, K. M., and Silva-Dias, M. A. F.: Smoking Rain Clouds over the Amazon, Science, 303, 1337-1342, 2004.

Ansmann, A., Wandinger, U., Riebesell, M., Weitkamp, C., and Michaelis, W.: Independent measurement of extinction and backscatter profiles in cirrus clouds by using a combined Raman elastic backscatter lidar, Appl. Optics, 31, 7113-7131, 1992.

Birmili, W., Heinke, K., Pitz, M., Matschullat, J., Wiedensohler, A., Cyrys, J., Wichmann, H.-E., and Peters, A.: Particle number size distributions in urban air before and after volatilisation, Atmos. Chem. Phys., 10, 4643-4660, doi:10.5194/acp-10-46432010, 2010.

Bosenberg, J., Matthias, V., Amodeo, A., Amoiridis, V., Ansmann, A., Baldasano, J. M., Balin, I., Balis, D., Bockmann, C., Boselli, A., Carlsson, G., Chaikovsky, A., Chourdakis, G., Comeron, A., De Tomasi, F., Eixmann, R., Freudenthaler, V., Giehl, H., Grigorov, I., Hagard, A., Iarlori, M., Kirsche, A., Kolarov, G., Komguem, L., Kreipl, S., Kumpf, W., Larcheveque, G., Linne,
H., Matthey, R., Mattis, I., Mekler, A., Mironova, I., Mitev, V., Mona, L., Muller, D., Music, S., Nickovic, S., Pandolfi, M., Papayannis, A., Pappalardo, G., Pelon, J., Perez, C., Perrone, R. M., Persson, R., Resendes, D. P., Rizi, V., Rocadenbosch, F., Rodrigues, J. A., Sauvage, L., Schneidenbach, L., Schumacher, R., Shcherbakov, V., Simeonov, V., Sobolewski, P., Spinelli, N., Stachlewska, I., Stoyanov, D., Trickl, T., Tsaknakis, G., Vaughan, G., Wandinger, U., Wang, X., Wiegner, M., Zavrtanik, M., and Zerefos, C., EARLINET: A European Aerosol Research Lidar Network to Establish an Aerosol Climatology, Max-PlanckInstitute (MPI) Report No. 348, 1-191, 2003.

Braslau, N. and Dave, J. V.: Effects of aerosols on the transfer of solar energy through realistic atmosphere. Part I: Nonabsorbing aerosols, J. Appl. Meteorol., 12, 610-615, 1973.

Che, H. Z., Shi, G. Y., Zhang, X. Y., Arimoto, R., Zhao, J. Q., Xu, L., Wang, B., and Chen, Z. H.: Analysis of 40 years of solar radiation data from China, 1961-2000, Geophys. Res. Lett., 32, L06803, doi:10.1029/2004GL022322, 2005.

Collis, R. T. H.: LIDAR: A new atmospheric probe, Q. J. Roy. Meteor. Soc., 92, 220-230, 1966.

Collis, R. T. H. and Russel, P. B.: Lidar measurement of particles and gases by elastic backscattering and differential absorption, in: Laser Monitoring of the Atmosphere, edited by: Hinkley, E. D., Springer, Berlin, 71-151, 1976.

Cooper, D. and Eichinger, W.: Structure of the atmosphere in an urban planetary boundary layer from lidar and radiosonde observations, J. Geophys. Res., 99, 22937-22948, 1994.

Del Gusta, M. and Marini, S.: On the retrieval of urban mass concentrations by a 532 and $1064 \mathrm{~nm}$ LIDAR, J. Aerosol Sci., 31, 1469-1488, 2000.

Devara, P. C. S., Raj, P. E., and Sharma, S.: Remote sensing of atmospheric aerosol in the nocturnal boundary layer, Environ. Pollut., 85, 97-102, 1994.

Directive 2008/50/EC of the European parliament and of the council of 21 May 2008 on ambient air quality and cleaner air for Europe, Official Journal of the European Union, L152, 30-35, 2008.

Eichinger, W., Cooper, D., Buttler, W., Cottingame, W., and Tellier, L.: Use of lidar for the evaluation of traffic-related urban pollution, Proc. SPIE, 209, 2102, doi:10.1117/12.170636, 1994.

Filipčič, A., Horvat, M., Veberič, D., Zavrtanik, D., and Zavrtanik, M.: Scanning lidar based atmospheric monitoring for fluorescence detectors of cosmic showers, Astropart. Phys., 18, 501512, 2003.

Gao, F., Bergant, K., Filipčič, A., Forte, B., Hua, D.-X., Song, X.Q., Stanič, S., Veberič, D., and Zavrtanik, M.: Observations of the atmospheric boundary layer across the land-sea transition zone using a scanning Mie lidar, J. Quant. Spectrosc. Ra., 112, 182188, 2011.

Garratt, J. R.: The atmospheric boundary layer, Cambridge Univ. Press, Cambridge, UK, 40-48, 1992.

Gasith, A. and Resh, V. H.: Streams in Mediterranean climate regions: Abiotic influences and biotic responses to predictable seasonal events, Annu. Rev. Ecol. Syst., 30, 51-81, 1999.

Grant, W. B.: Laser remote sensing techniques, in: Laser spectroscopy and its applications, edited by: Radziemski, L. J., Solarz, R. W., and Paisner, J. A., Marcel Dekker, New York, 565621, 1987.

Hair, J. W., Hostetler, C. A., Cook, A. L., Harper, D. B., Ferrare, R. A., Mack, T. L., Welch, W., Izquierdo, L. R., and Ho- 
vis, F. E.: Airborne High Spectral Resolution Lidar for profiling aerosol optical properties, Appl. Optics, 47, 6734-6752, 2008.

Hamilton, P. M.: Lidar measurement of backscatter and attenuation of atmospheric aerosol, Atmos. Environ., 3, 221-223, 1969.

Harrison, R. M., Jones, M., and Collins, G.: Measurements of the physical properties of particles in the urban atmosphere, Atmos. Environ., 33, 309-321, 1999.

Harshvardhan: Aerosol-Climate interactions, in: Aerosol-CloudClimate Interactions, edited by: Hobbs, P. V., Academic Press, San Diego, California, 75-95, 1993.

He, T.-Y., Gao, F., Stanič, S., Veberič, D., Bergant, K., Dolžan, A., and Song, X.-Q.: Scanning mobile lidar for aerosol tracking and biological aerosol identification, Proc. SPIE, 7832, 7832U, doi:10.1117/12.868387, 2010.

Hofmann, D. J.: Twenty years of balloon borne tropospheric aerosol measurements at Laramie, Wyoming, J. Geophys. Res., 98, 12753-12766, 1993.

Intergovernmental Panel on Climate Change (IPCC): Climate Change 2007: in: The Scientific Basis, edited by: Solomon, S., Qin, D., Manning, M., Chen, Z., Marquis, M., Averyt, K. B., Tignor, M., and Miller, H. L., Cambridge Univ. Press, New York, USA, 131-336, available at: http: //www.ipcc.ch/publications_and_data/publications_ipcc_fourth_ assessment_report_wg1_report_the_physical_science_basis.htm, 2007.

Kano, M.: On the determination of backscattered and extinction coefficient of the atmosphere by using laser radar, Pap. Meteorol. Geophys., 19, 121-129, 1968.

Kaufman, Y. J., Tanre, D., and Boucher, O.: A satellite view of aerosols in the climate system, Nature, 419, 215-223, 2002.

Killinger, D. K. and Menyuk, N.: Laser remote sensing of the atmosphere, Sciencs, 235, 37-45, 1987.

Klett, J. D.: Stable analytical inversion solution for processing lidar returns, Appl. Optics, 20, 211-220, 1981.

Kovalev, V. A. and Eichinger, W. E.: Elastic Lidar: Theory, Practice and Analysis Methods, Wiley and Sons, New York, 295-329, 2004.

Lagrosas, N., Kuze, H., Takeuchi, N., Fukagawa, S., Bagtasa, G., Yoshii, Y., Naito, S., and Yabuki, M.: Correlation study between suspended particulate matter and portable automated lidar data, J. Aerosol Sci., 36, 439-454, 2005.

Lewandowski, P. A., Eichinger, W. E., Holder, H., Prueger, J., Wang, J., and Kleinman, L. I.: Vertical distribution of aerosols in the vicinity of Mexico City during MILAGRO-2006 Campaign, Atmos. Chem. Phys., 10, 1017-1030, doi:10.5194/acp-10-10172010, 2010.

$\mathrm{Li}, \mathrm{Z}$.: Influence of absorbing aerosols on the inference of solar surface radiation budget and cloud absorption, J. Climate, 11, 5-17, 1998.

Measures, R. M.: Laser Remote Sensing: Fundamentals and Applications, Wiley, New York, 1984.
Measures, R. M.: Laser Remote Chemical Analysis, Wiley, New York, 1-83, 1988.

Menut, L., Flamant, C., Pelon, J., Valentin, R., Flamant, P. H., Dupont, E., and Carissimo, B.: Study of the boundary layer structure over the Paris agglomeration as observed during the ECLAP Experiment, in: Advances in atmospheric remote sensing with lidar, edited by: Ansmann, A., Neuber, R., Rairoux, P., and Wandinger, U., Springer, Berlin, 15-18, 1997.

Min, C.: Local level set method in high dimension and codimension, J. Comput. Phys., 200, 368-382, 2004.

Muller, D., Ansmann, A., Mattis, I., Tesche, M., Wandinger, U., Althausen, D., and Pisani, G.: Aerosol-type-dependent lidar-ratio observed with Raman lidar, J. Geophys. Res., 112, D16202, doi:10.1029/2006JD008292, 2007.

PerkinElmer Datasheet: Long wavelength Enhanced Silicon APD, C30954EH, C30955EH and C30956EH Series, available at: www.excelitas.com/downloads/ DTS_LongWLEnSiliconAPDSeries.pdf (last access: May 2012), 2011.

Rosenfeld, D.: Suppression of rain and snow by urban and industrial air pollution, Science, 287, 1793-1796, 2000.

Spinhirne, J. D.: Micro pulse lidar, IEEE T. Geosci. Remote, 31, 48-55, 1993.

Spinhirne, J. D., Reagan, J. A., and Herman, B. M.: Vertical distribution of aerosol extinction cross section and inference of aerosol imaginary index in the troposphere by lidar technique, J. Appl. Meteorol., 19, 426-438, 1980.

Spuler, S. M. and Mayor, S. D.: Scanning eye-safe elastic backscatter lidar at 1.5-micron wavelength, J. Atmos. Ocean. Tech., 22, 696-703, 2005.

Twomey, S. A., Davidson, K. A., and Seton, K. J.: Results of 5 years of observations of cloud nucleus concentrations at Robertson, New South Wales, J. Atmos. Sci., 35, 650-656, 1978.

Winker, D. M., Hunt, W. H., and McGill, M. J.: Initial performance assessment of CALIOP, Geophys. Res. Lett., 34, L19803, doi:10.1029/2007GL030135, 2007.

Winker, D. M., Vaughan, M. A., Omar, A., Hu, Y., Powell, K. A., Liu, Z., Hunt, W. H., and Young, S. A. Overview of the CALIPSO mission and CALIOP data processing algorithms, J. Atmos. Ocean. Tech., 26, 2310-2323, doi:10.1175/2009JTECHA1281.1, 2009.

Winker, D. M., Pelon, J., Coakley Jr., J. A., Ackerman, S. A., Charlson, R. J., Colarco, P. R., Flamant, P., Fu, Q., Hoff, R., Kittaka, C., Kubar, T. L., LeTreut, H., McCormick, M. P., Megie, G., Poole, L., Powell, K., Trepte, C., Vaughan, M. A., and Wielicki, B. A.: The CALIPSO Mission: A Global 3D View of Aerosols and Clouds, B. Am. Meteorol. Soc., 91, 1211-1229, 2010.

Wu, Z., Hu, M., Lin, P., Liu, S., Wehner, B., and Wiedensohler, A.: Particle number size distribution in the urban atmosphere of Beijing, China, Atmos. Environ., 42, 7967-7980, 2008. 